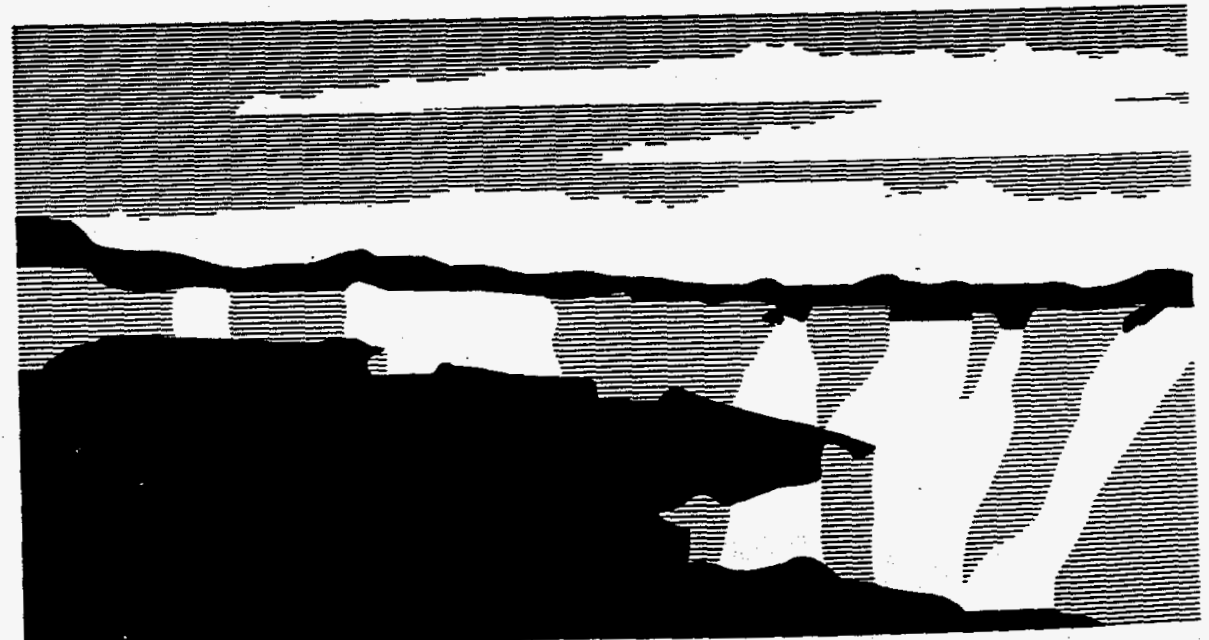

Les Alamos National Laboratory, an affirmative action/equal opportunity employer, is operated by the University of California for the U.S. Department of Energy under contract W-7405-ENG-36. By acceptance of this article, the publisher recognizes that the U.S. Govemment retains a nonexchusive, royalty-free license to under contract $W$ reproduce the published form of this contribution, or to allow others to do so, for U.S. Government purposes. The Los Alamos National Laboratory requests that the publisher identity this articte as work pertormed under the auspices of the U.S. Department of Enengy. 


\section{DISCLAIMER}

This report was prepared as an account of work sponsored by an agency of the United States Government. Neither the United States Government nor any agency thereof, nor any of their employees, makes any warranty, express or implied, or assumes any legal liability or responsibility for the accuracy, completeness, or usefulness of any information, apparatus, product, or process disclosed, or represents that its use would not infringe privately owned rights. Reference herein to any specific commercial product, process, or service by trade name, trademark, manufacturer, or otherwise does not necessarily constitute or imply its endorsement, recommendation, or favoring by the United States Government or any agency thereof. The views and opinions of authors expressed herein do not necessarily state or reflect those of the United States Government or any agency thereof. 


\section{DISCLAMMER}

Portions of this document may be illegible in electronic image products. Images are produced from the best available original document. 


\title{
END-ON RADIOISOTOPE THERMOELECTRIC GENERATOR IMPACT TESTS
}

\author{
M. A. H. Reimus and J. E. Hinckley \\ Los Alamos National Laboratory \\ P. O. Box 1663, MS-E502 \\ Los Alamos, NM 87545 \\ (505) 665-7296 (505) 667-9931
}

\begin{abstract}
$\underline{\text { Abstract }}$
The General-Purpose Heat Source (GPHS) provides power for space missions by transmitting the heat of ${ }^{238} \mathrm{Pu}$ decay to an array of thermoelectric elements in a radioisotope thermoelectric generator (RTG). The modular GPHS design was developed to address both survivability during launch abort and return from orbit. The first two RTG Impact Tests were designed to provide information on the response of a fully loaded RTG to end-on impact against a concrete target. The results of these tests indicated that at impact velocities up to $57 \mathrm{~m} / \mathrm{s}$ the converter shell and internal components protect the GPHS capsules from excessive deformation. At higher velocities, some of the internal components of the RTG interact with the GPHS capsules to cause excessive localized deformation and failure.
\end{abstract}

\section{INTRODUCTION}

The General-Purpose Heat Source (GPHS) is a modular component of the radioisotope thermoelectric generators (RTGs) that will provide power for the National Aeronautics and Space Administration's (NASA's) Cassini mission to Saturn. An RTG generates electric power by using the heat of ${ }^{238} \mathrm{Pu}$ a-decay to create a temperature differential across a thermoelectric array. Each RTG is loaded with 18 GPHS modules, and each GPHS module (Figure 1) contains four ${ }^{238} \mathrm{PuO}_{2}$ fuel pellets that provide a total thermal output of $250 \mathrm{~W}$. Each fuel pellet is encapsulated in a vented, DOP-26 iridium alloy shell. Two capsules are held in a Fineweave-Pierced Fabric (FWPF, a 3-D carbon/carbon composite, product of AVCO Systems Division, 201 Lowell St., Wilmington, MA 01887) graphite impact shell (GIS), and two GISs are contained within an FWPF aeroshell.

The modular GPHS design was developed to address both survivability during launch abort and return from orbit. Previous testing conducted in support of the Galileo and Ulysses missions documented the response of the GPHS heat source to a variety of fragment-impact, aging, atmospheric reentry, and Earth impact conditions (Schonfeld 1984, Schonfeld and George 1984a, Schonfeld and George 1984b, George and Schonfeld 1984a, George and Schonfeld 1984b, Pavone et al. 1985, George and Pavone 1985, and George and Pavone 1986). Tests that required field testing of heat source and RTG components (such as solid-propellent fire, explosive overpressure, large fragment interaction, etc.) were performed using GPHS capsules fueled with ${ }^{238} \mathrm{UO}_{2}\left({ }^{235} \mathrm{U}\right.$-depleted) (George et al. 1985, George 1986, Cull et at. 1986, Cull and Pavone 1986, and George 1987).

The end-on RTG impact tests were designed to evaluate the response of GPHSs, GPHS modules and loaded radioisotope thermoelectric generators (RTGs) to conditions that may be experienced as a result of potential on- and near-pad accidents involving failures of the Cassini spacecraft and/or launch vehicle. Specifically, these impact tests were designed to provide information on the response of a loaded RTG to end-on impact against concrete typical of installations at Kennedy Space Center. These tests also utilized GPHS capsules fueled with ${ }^{238} \mathrm{UO}_{2}$. This report summarizes the results of these tests. The reader is referred to a previous report for more detail (Reimus et al. 1996).

\section{BACKGROUND}

The urania pellets used in this study were fabricated from urania powder produced by Oak Ridge National Laboratory (urania lot \# NF-30-4225). All of the pellets used were fabricated by cold pressing followed by sintering.

The graphite components used in the test series were obtained from EG\&G Mound Applied Technologies (EG\&G MAT). Each of the converter sections was loaded with a stack made up of eight FWPF graphite modules and one POCO (polycrystalline graphite) module that was 0.24 in. less than full module height. This POCO module, 
designated number 9, was located at the end of the stack opposite the RTG dome (the impacted end) and contained a molybdenum disc with mass equivalent to that of four simulant-fueled GPHSs. In the first end-on RTG impact test (RTG-1), the first three modules (number 1 is at the impact end) were fabricated from FWPF graphite and contained FWPF graphite GISs loaded with urania-fueled GPHSs with flight-quality iridium cladding. Modules 4 and 5 were fabricated of FWPF graphite and contained POCO grade AXF 5Q GISs loaded with urania-fueled GPHSs with engineering quality iridium cladding. Modules 6,7 , and 8 consisted of FWPF graphite modules containing. POCO grade AXF 5Q GISs loaded with molybdenum slugs fabricated with GPHS exterior dimensions. In the second end-on RTG impact test (RTG-2), the first four modules were fabricated from FWPF graphite and contained FWPF GISs loaded with urania-fueled GPHSs with flight-quality iridium. Modules 5 and 6 were fabricated of FWPF and contained POCO AXF 5Q GISs loaded with urania-fueled GPHSs with engineering quality iridium. Modules 7 and 8 are similar to 5 and 6 with the exception of being loaded with molybdenum slugs.

The modules consisted of FWPF aeroshells containing two GISs designated as A and C. The A GIS is inserted in the A GIS cavity. This cavity is identified by a small dimple on the face of the aeroshell that has flight control bevels machined on the edges. The dimple is located on the corner of the face closest to the A GIS cavity end cap.

The concrete target for each test was 36 in. $\times 48$ in. $\times 18$ in. thick. The concrete was provided by the US Air Force at Cape Canaveral. It is typical of the concrete used for launch pads and other installations in the area. Each concrete slab was oriented with the 36 in. edge horizontal and the 48 in. edge vertical. This face was centered across the sled track.

The RTG converter shells used in these tests were provided by Lockheed Martin. Each one consisted of approximately one half of a converter housing. The outboard end of the converter, which was impacted against the concrete, included the heat source support system (including end foil insulation) and the pressure dome.

\section{EXPERIMENTAL PROCEDURES}

The tests were conducted at the Sandia National Laboratory (SNL) Rocket Sled Test Track area, within Area III. The test hardware consisted of the furnace and its support stand, the rocket sled, the aperture plate, and the concrete block. The furnace, designed to heat its contents in an argon atmosphere, had Canthol elements that were conditioned to reach $1200-1250^{\circ} \mathrm{C}$. The furnace had a bottom "door" that could be remotely operated so that the graphite stack could be lowered from the furnace into the converter housing. The support stand was a steel structure that supported the furnace and the graphite stack lowering apparatus. The sled was designed to compress as it impacted the aperture plate. The aperture plate was designed to stop the sled while allowing the RTG housing to pass through an opening to the concrete target. The key features on the sled included the support/rotation shafts, the rear latch mechanism, the shaft rotation DC motor and its corresponding counter weight. The shafts supported the RTG housing and rotated the housing from vertical to horizontal orientation. Hinges in the shafts were designed to allow the shafts to travel forward through access slots in the mounting block as the sled impacted the aperture plate (Figures 2 and 3). The rear latch mechanism locked the RTG assembly in the horizontal orientation and held it in place while it was propelled down the sled track. The counter weight balanced the weight across the sled, thereby ensuring a uniform compression of the sled upon impact with the aperture plate.

The graphite module stacks were heated to approximately $1210^{\circ} \mathrm{C}$. The rockets were readied and the test sequence began with the remote opening of the furnace door. The stack was then remotely lowered from the furnace into the RTG housing attached to the test sled. The lowering sequence was completed when the latches on top of the housing section engaged, securing the stack within. The RTG was then rotated 90 degrees into the end-on configuration and latched into place with the rear latch mechanism. After the appropriate amount of time had passed for the clads inside the stack to cool to nominally $1093^{\circ} \mathrm{C}$ (approximately one minute), the rockets on the sled were fired, propelling the sled and its components down the track and into the aperture plate (approximately $1.5 \mathrm{sec}$ ). Upon impact with the aperture plate, the sled was stopped and the RTG released through the aperture and impacted the concrete target. The stack cooling characteristics were measured prior to testing at LANL and at the test site at SNL. 


\section{RESULTS}

\section{First End-on Impact Test:_RTG-1}

One half of a Cassini RTG was impacted on April 13, 1995. The impact velocity was $57.6 \pm 0.3 \mathrm{~m} / \mathrm{s}$ and the RTG graphite module stack temperature was $1071 \pm 5^{\circ} \mathrm{C}$.

The converter rebounded after impact with a modest twisting of the trailing end. The trailing end struck the cushioned rear side of the aperture plate through which the converter traveled upon release from the sled. Most of the failure in the converter housing took place in the upper end of the outboard end above the circumferential. This rib was located $2.95 \mathrm{in}$. from the outboard end flange. There was considerable breakup of the module stack inside the converter. A piece of the stack tie rod and fitting, along with one intact module (Module 9), was ejected from the back end of the converter housing. Intact Modules 8, 7, and 6 fell free from the converter after the test as it was moved to accommodate an argon flush to prevent oxidation of graphite components in the converter.

The Module 1 and 2 aeroshells were shattered into several pieces. All GISs from these two aeroshells were also shattered into several pieces. One of the arms of the titanium heat source support assembly in the converter housing failed. Two of the heat source support assembly's four stand-offs were also broken. These stand-offs are the probable cause of the higher deformation of the A GISs of Modules 1 and 2.

Deformations of the capsules recovered from modules 1,2, and 3 are listed in Table 1 . The largest deformations were experienced by the Module 1 clads, as expected. No visible cracks or breeches were observed in any of the clads. Based on historical data, one would expect the strains reported for the capsules in Module 1 to have resulted in breaching cracks.

TABLE 1. RTG-1 Capsule Strains

\begin{tabular}{|c|c|c|c|c|c|c|}
\hline \multirow[b]{3}{*}{ Module } & \multirow[b]{3}{*}{ GPHS } & \multirow[b]{3}{*}{ Axial } & \multicolumn{4}{|c|}{ STRAIN, $\%^{\mathrm{a}}$} \\
\hline & & & \multicolumn{2}{|c|}{ Vent Cup, Diametral } & \multicolumn{2}{|c|}{ Shield Cup, Diametral } \\
\hline & & & Max. & Min. & Max. & Min. \\
\hline 1 & SC0077 & 8.30 & 12.60 & -15.08 & 10.71 & -4.28 \\
\hline 1 & SC0076 & 19.48 & 20.57 & -17.14 & 15.94 & -11.31 \\
\hline 1 & SC0079 & 5.84 & 9.34 & -2.06 & 6.26 & -3.77 \\
\hline 1 & SC0078 & 5.93 & 11.65 & -8.65 & 10.37 & -5.14 \\
\hline 2 & SC0081 & 2.12 & 6.34 & -6.51 & 4.03 & -1.03 \\
\hline 2 & SC0080 & 8.72 & 13.28 & -7.80 & 8.40 & -5.91 \\
\hline 2 & SC0083 & 4.91 & 4.88 & -3.94 & 4.88 & -3.34 \\
\hline 2 & SC0082 & 2.88 & 6.94 & -7.88 & 4.71 & -1.20 \\
\hline 3 & SC0085 & 2.29 & 1.63 & -4.37 & 1.29 & -0.51 \\
\hline 3 & SC0084 & 1.78 & 3.34 & -3.94 & 2.49 & -1.80 \\
\hline 3 & SC0088 & 1.35 & 1.37 & -4.11 & 0.94 & -1.80 \\
\hline 3 & SC0087 & 1.02 & 0.86 & $-2,40$ & 0.94 & -1.63 \\
\hline
\end{tabular}

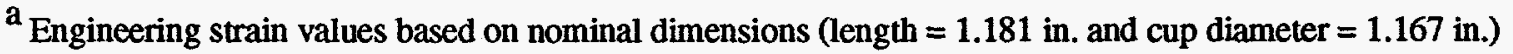

Clad SC0076 was located in the blind end of the A GIS in Module 1 (Figure 4). This clad had the most deformation, as indicated by strain calculations, of the clads impacted in this test. In spite of its relatively large deformation, neither SCO076 nor any other clad breached. The impact face of this clad was centered at approximately 270 degrees from the weld start. Because this clad was the most highly deformed, it was selected for metallographic examination. It was defueled and the fuel submitted for particle size analysis.

Metallographic examination of the vent revealed typical microstructure. No anomalies were observed in the vent microstructure. The microstructures of the single-pass weld and weld overlap areas were typical of the 
microstructures usually observed in these areas. The microstructures of the vent and shield cup walls were also typical. The fuel particle size analysis is given in Table 2 .

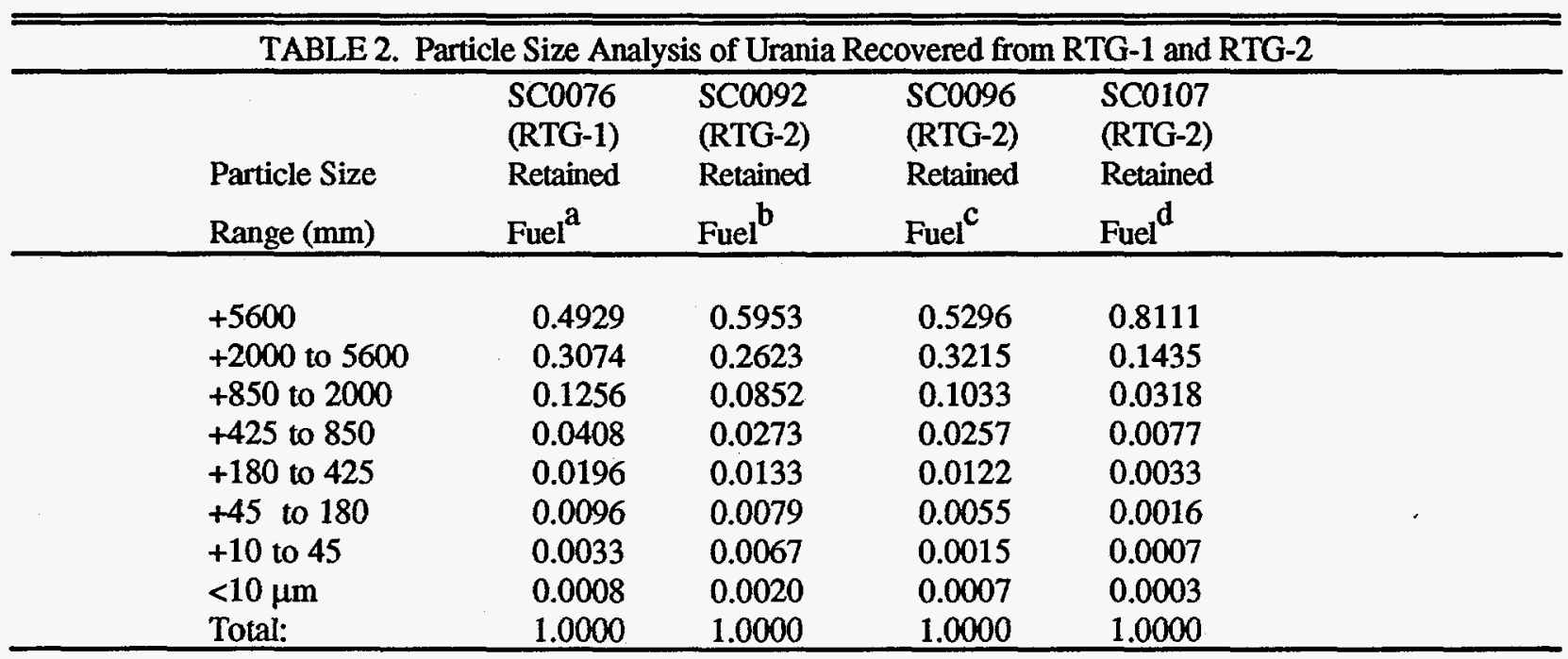

${ }^{\mathrm{a}}$ No fuel released.

${ }^{b}$ Approximately $12.164 \mathrm{~g}$ fuel released.

'Approximately $0.229 \mathrm{~g}$ fuel released.

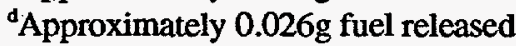

\section{Second End-on Impact Test: RTG-2}

One half of a Cassini RTG was impacted on May 24, 1995. The impact velocity was $77.1 \mathrm{~m} / \mathrm{s}$ and the RTG graphite module stack temperature was $1090 \pm 5^{\circ} \mathrm{C}$. Deformations of the capsules recovered from modules 1,2 and 3 are listed in Table 3.

TABLE 3. RTG-2 Capsule Strains

\begin{tabular}{|c|c|c|c|c|c|c|}
\hline \multirow[b]{2}{*}{ Module } & \multirow[b]{2}{*}{ GPHS } & \multirow[b]{2}{*}{ Axial } & \multicolumn{2}{|c|}{ STRAIN, $\%^{\mathrm{a}}$} & \multicolumn{2}{|c|}{ Shield Cup, Diametral } \\
\hline & & & Max. & Min. & Max. & Min. \\
\hline 1 & SC0090 & 4.10 & 7.28 & -7.03 & 6.77 & -3.34 \\
\hline 1 & SC0089 & 10.65 & 12.51 & -14.48 & 10.11 & -8.83 \\
\hline 1 & SC0092 & 14.98 & $\mathbf{N M}^{\mathrm{b}}$ & $\mathbf{N M}^{\mathbf{b}}$ & 10.03 & -4.28 \\
\hline 1 & SC0091 & 5.87 & 10.45 & -12.00 & 5.48 & -5.31 \\
\hline 2 & SC0094 & 2.47 & 4.71 & -5.91 & 2.57 & -2.31 \\
\hline 2 & SC0093 & 1.95 & 3.43 & -2.48 & 2.48 & -2.31 \\
\hline 2 & SC0096 & 21.48 & 10.37 & -17.40 & 9.43 & -11.48 \\
\hline 2 & SC0095 & 5.18 & 7.71 & -11.31 & 6.68 & -7.03 \\
\hline 3 & SC0103 & 2.04 & 2.83 & -4.63 & 2.48 & -1.37 \\
\hline 3 & SC0097 & 2.47 & 3.94 & -4.20 & 4.03 & -2.31 \\
\hline 3 & SC0105 & 3.90 & 3.00 & -7.63 & 3.26 & -5.06 \\
\hline 3 & SC0104 & 4.24 & 4.28 & -6.43 & 4.54 & -7.71 \\
\hline
\end{tabular}

'Engineering strain values based on pre-impact nominal dimensions (length $=1.181 \mathrm{in}$. and cup diameter $=1.167$ in.) 
Not measureable, parts of the cup missing.

There was considerable failure of the converter housing at the impacted end. The impact resulted in compaction of the housing by approximately six inches. The converter end cap was sheared off and found lying beside the converter (Figure 8). Several of the end cap bolts embedded in the face of the concrete target. Four modules were ejected from the back of the converter.

Four clads were ejected out the front (impacted) end of the converter. Three of these had breaching cracks in the iridium clads. One of the breached clads, SC0092, was missing approximately 1/4 of the vent cup cladding. Another breached clad, SC0096, had a large transverse indentation above the weld on the vent cup. The clad deformation appeared to be caused by the titanium heat source support assembly located in the front end of the converter housing. The remaining breached clad, SC0107, had a weld centerline crack. The fuel was recovered from the three breached clads and submitted for particle size analysis; listed in Table 2.

SC0092 was located in the open end of the C GIS in Module 1. The impact face of the clad was centered at approximately 0 degrees at the weld start. A large piece of the vent cup was torn off during the impact (Figure 9). The area of this breach was measured to be approximately $485 \mathrm{~mm}^{2}$. This clad was defueled but not submitted for metallography.

SC0096 was located in the open end of the C GIS in Module 2 (Figure 10). A transverse breaching crack was located in the vent cup in the impact face ( 0 degrees from weld start. The crack appears to have been caused by impact with the relatively sharp edge of an external component upon impact. A titanium heat source support assembly was located in the front end of the converter housing. The widest area of the crack appeared to have been pushed open by fragmentation of the simulant fuel pellet beneath the clad wall.

Metallographic examination of the vent revealed typical microstructure. No anomalies were observed in the vent microstructure. The microstructure of the breached area revealed intergranular failure. The microstructure along the crack edge shows thinning of the clad wall and grain elongation. The microstructures of the single-pass weld and weld overlap areas were typical of the microstructures usually observed in these areas. The microstructures of the vent and shield cup walls were also typical.

SC0107 was one of three simulant-fueled clads that breached. SC0107 was located in the open end of the C GIS in Module 4. The impact face was centered at approximately 200 degrees from the weld start. A weld centerline crack was centered at approximately 90 degrees from weld start, spanning from approximately 45 to 135 degrees. The weld shield was also breached and the urania was visible through the crack. The crack was centered between two flattened areas of the clad and appears to have been caused by compression of the clad.

Metallographic examination of the vent revealed typical microstructure. No anomalies were observed in the vent microstructure. The microstructure of the breached area revealed a clean intergranular fracture with little, if any, wall thinning and grain elongation. Fusion of the weld shield to the weld was also observed in this location. The microstructure along the crack edge shows cleavage between the grains typical of iridium failure The microstructures of the single-pass weld and weld overlap areas were typical of the microstructures usually observed in these areas. The microstructures of the vent and shield cup walls was also typical.

\section{DISCUSSION}

\section{Impact Response and Fuel Release}

There were no capsule failures in test RTG-1, although four capsules experienced dimensional strains greater than 10\%. These capsules were located in Modules 1 and 2 on the impact end of the converter. One capsule in particular, SC0076, had a diametral strain above $20 \%$. This strain would be expected to result in a failure. Previous testing with simulant-fueled capsules, in the cold-process verification (CPV) test series, resulted in failures at strains ranging from 12 to $16 \%$ (Reimus and George 1996). However, a full module impact in the CPV test series, at 54 $\mathrm{m} / \mathrm{s}$, did not result in clad failures.

Three of the capsules in test RTG-2 had capsule failures. Two of the clads, SC0092 and SC0096, appeaned to fail due to contact with the titanium heat source support assembly. Capsule SC0092 had a large failure area (485 $\mathrm{mm}^{2}$ ) that resulted in a release of approximately $12 \mathrm{~g}$ of simulant fuel. Capsule SC0096 had a much smaller failure that resulted in a release of approximately $0.2 \mathrm{~g}$ of simulant fuel. Capsule SC0107 experienced a weld failure. The intergranular failure occurred between columnar grains located in the weld centerline. Fusion of the weld with the 
weld shield was also evident in this location. This failure appeared to be the result of fragment push-through and resulted in a release of approximately $0.026 \mathrm{~g}$.

The releases from SC0092 and SC0096 are higher, from two to 120 times greater than releases observed in previous tests, such as the CPV test series (Reimus and George 1996). The breaches of these capsules were also relatively larger than those observed in previous tests. This appears to be caused by the different geometry of the impact "target". The RTG-1 clads appeared to impact against an arm of the titanium heat source support assembly, whereas the CPV clads were impacted against a flat, hardened steel target. The release from SC0107 is smaller than previous releases and the breach area is within the range of those observed in the CPV test series. There was no evidence that this clad impacted on the support assembly.

\section{Pellet Fragmentation.}

Based on data presented in Table 2, there is a slight difference between the particle size profiles of urania recovered from RTG-1 (SC0076) and two of the breached clads recovered from RTG-2 (SC0092 and SC0096). The most significant difference is in the $\leq 10 \mathrm{~mm}$ range size. The fraction of urania recovered from SC0092 is just over twice the amount recovered from SC0076 and SC0096. However, the magnitude of these weight fractions are very small in comparison to the weight fractions measured in the CPV tests (two to 9.2 times smaller) (Reimus and George 1996).

There is a significant difference between the fragmentation of SC0107, recovered from RTG-2, and the other clads recovered from RTG-1 and RTG-2. The fraction of urania recovered from SC0107 in the $+5600 \mathrm{~mm}$ range is almost twice that recovered from SC0076, SC0092, and SC0096. Capsule SC0107 did not undergo the same magnitude of deformation as the others. Because the clad was not deformed as severely as the other clads, the fuel pellet would not be expected to be as fragmented as the other fuel pellets.

\section{CONCLUSIONS}

1. Impact of one half of a converter housing loaded with simulant GPHSs at $57.6 \mathrm{~m} / \mathrm{s}$ resulted in no GPHS clad failures.

2. Impact of the converter housing loaded with simulant GPHSs at $77.1 \mathrm{~m} / \mathrm{s}$ resulted in the failure of three GPHSs. Two of the failures appear to have been caused by impact with the titanium heat source support assembly.

3. The results suggest that the RTG and graphite components surrounding the GPHS protect against clad failure at velocities up to $57 \mathrm{~m} / \mathrm{s}$. This protection appears to be overcome at higher impact velocities, allowing GPHS clads to impact with converter housing components that have unfavorable strength/hardness and geometry, thereby resulting in clad failures.

\section{Acknowledgments}

We thank A. Herrera, M. Barney, and D. Montoya for designing and conducting the field tests, and T. Baros, E. Burciaga, C. Lynch, P. Moniz, and M. Padilla for performing metallography, sample preparation, and particle size analyses. We would like to give special thanks to B. Kampfe and F. Mathews of Sandia National Laboratory for

design of the sleds and coordination of tests at the Sandia sled test facility. This work was supported by the Department of Energy, Office of Nuclear Energy.

\section{References}

Cull, T. A., T. G. George, and D. Pavone (1986) General-Purpose Heat Source Development: Safety Verification Test Program; Explosion Overpressure Test Series, LA-10697-MS, Los Alamos National Laboratory, Los Alamos, NM.

Cull, T. A. and D. Pavone (1986) General-Purpose Heat Source Development: Safety Verification Test Program; Flyer Plate Test Series, LA-10742-MS, Los Alamos National Laboratory, Los Alamos, NM. 
George, T. G. (1987) General-Purpose Heat Source Development: Safety Verification Test Program; Edge-On Flyer Plate Tests, LA-10872-MS, Los Alamos National Laboratory, Los Alamos, NM.

George, T. G. (1986) General-Purpose Heat Source Development: Safety Verification Test Program; Titanium Bullet/Fragment Test Series, LA-10724-MS, Los Alamos National Laboratory, Los Alamos, NM.

George, T. G and D. Pavone (1985) General-Purpose Heat Source Safety Verification Test Series: SVT-7 Through SVT-10, LA-10408-MS, Los Alamos National Laboratory, Los Alamos, NM.

George, T. G. and D. Pavone (1986) General-Purpose Heat Source Safety Verification Test Series: SVT-I1 Through SVT-13, LA-10710-MS, Los Alamos National Laboratory, Los Alamos, NM.

George, T. G and F. W. Schonfeld (1984a) General-Purpose Heat Source Development: Safety Test Program, Postimpact Evaluation, Design Iteration Test 4, LA-10217-SR, Los Alamos National Laboratory, Los Alamos, NM.

George, T. G. and F. W. Schonfeld (1984b)General-Purpose Heat Source Development: Safety Test Program, Postimpact Evaluation, Design Iteration Test 5, LA-10232-SR, Los Alamos National Laboratory, Los Alamos, NM.

George, T. G., R. E. Tate, and K. M. Axler (1985) General-Purpose Heat Source Development: Safety Verification Test Program; Bullet/Fragment Test Series, LA-10364-MS, Los Alamos National Laboratory, Los Alamos, NM.

Pavone, D, T. G. George, and C. E. Frantz (1985) General-Purpose Heat Source Safety Verification Test Series: SVT-1 Through SVT-6, LA-10353-MS, Los Alamos National Laboratory, Los Alamos, NM.

Reimus, M. A. H. and T. G. George (1996) General-Purpose Heat Source: Research and Development Program; Cold-Process Verification Test Series, LA-13118-MS, Los Alamos National Laboratory, Los Alamos, NM.

Reimus, M. A. H., J. E. Hinckley, and T. G. George (1996) General-Purpose Heat Source: Research and Development Program; Radioisotope Thermoelectric Generator Impact Tests: RTG-1 and RTG-2, LA-13147, Los Alamos National Laboratory, Los Alamos, NM.

Schonfeld, F. W. (1984) General-Purpose Heat Source Development: Safety Test Program, Postimpact Evaluation, Design Iteration Test 1, LA-9680-SR, Los Alamos National Laboratory, Los Alamos, NM.

Schonfeld, F. W. and T. G. George (1984a) General-Purpose Heat Source Development: Safety Test Program, Postimpact Evaluation, Design Iteration Test 2, LA-10012-SR, , Los Alamos National Laboratory, Los Alamos, NM.

Schonfeld, F. W. and T. G. George (1984b) General-Purpose Heat Source Development: Safety Test Program, Postimpact Evaluation, Design Iteration Test 3, LA-10034-SR, Los Alamos National Laboratory, Los Alamos, NM. 

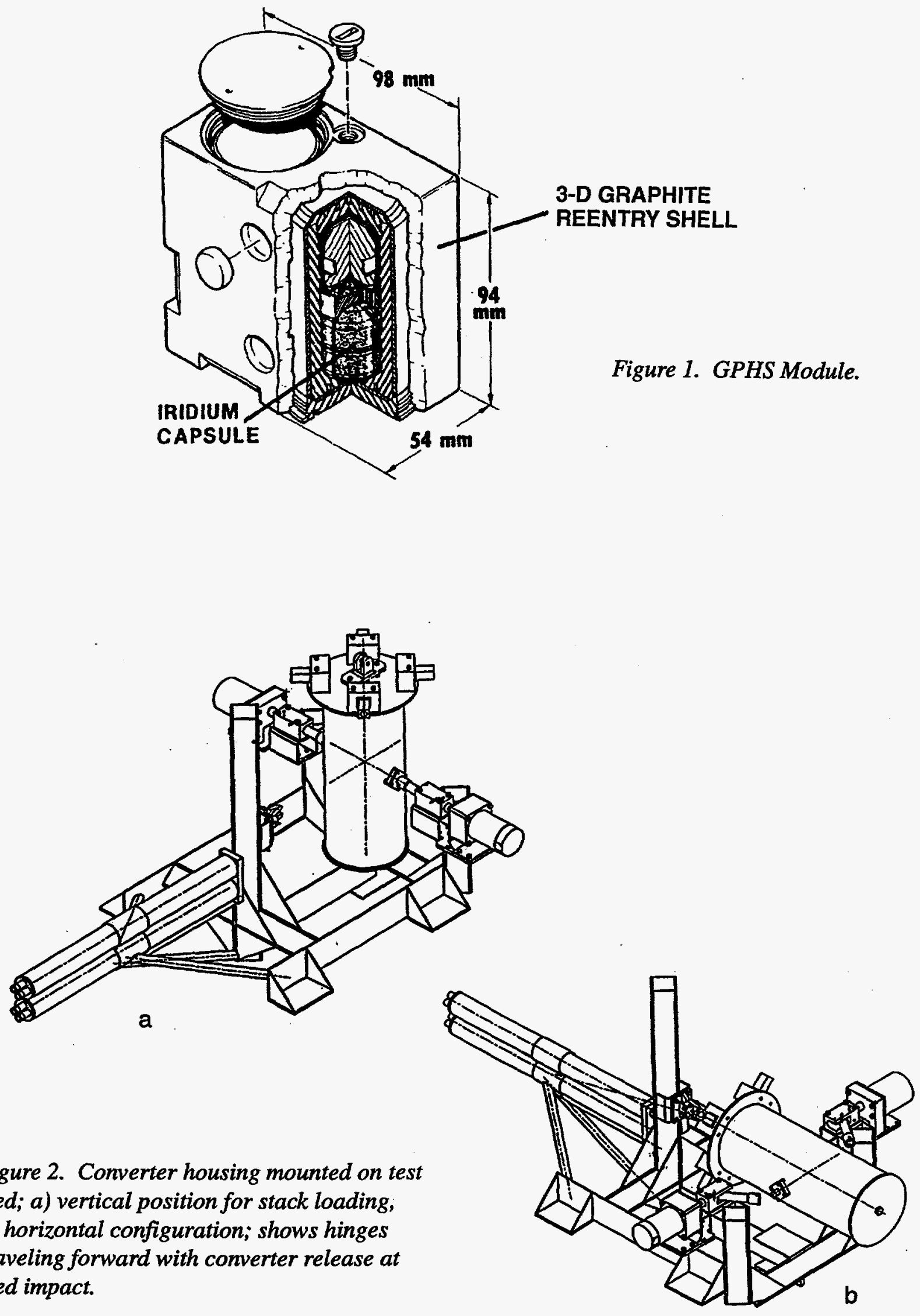


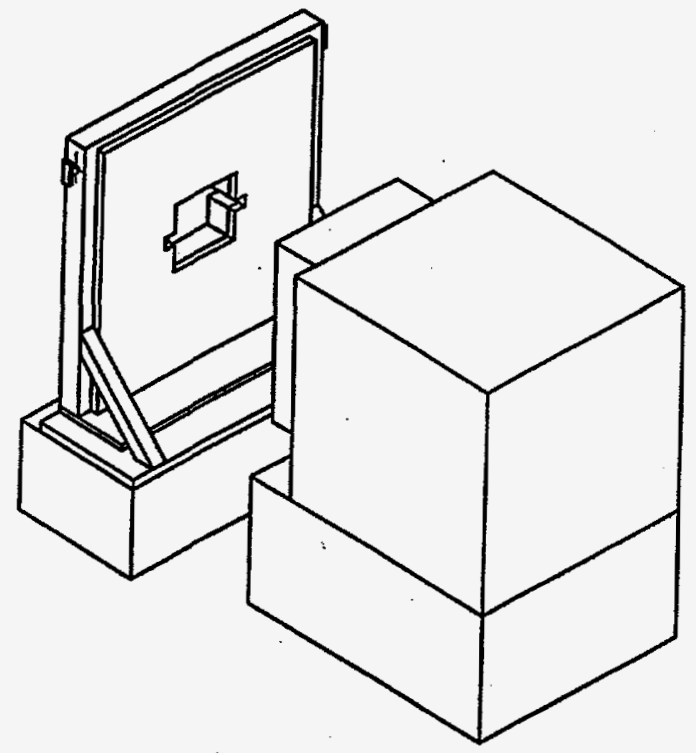

Figure 3. Aperture plate and concrete target.

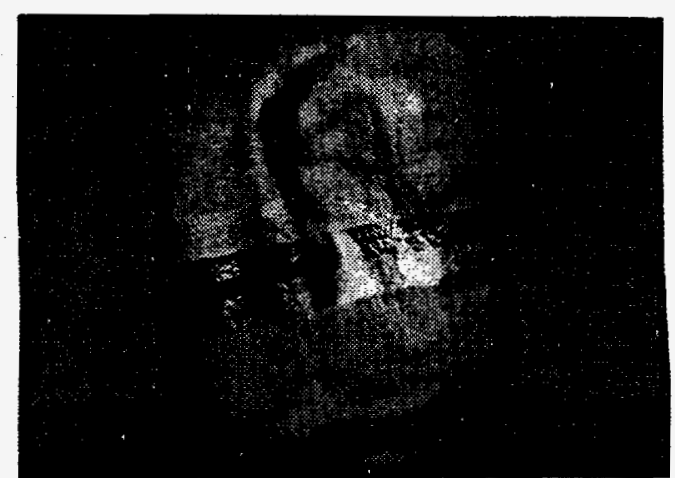

(a)

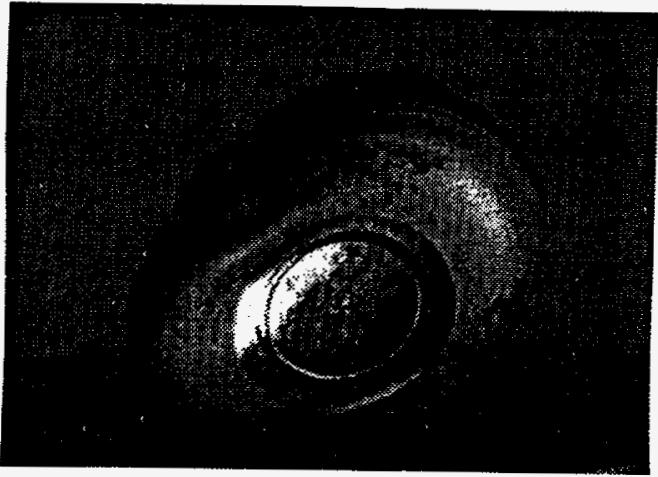

(b)

Figure 4. SC0076 experienced the greatest amount of strain in Test RTG-1; (a) impact face, (b) vent end.

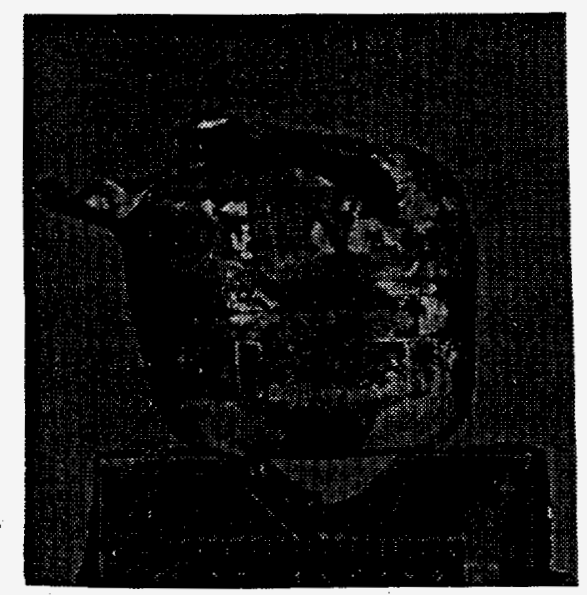

(a)

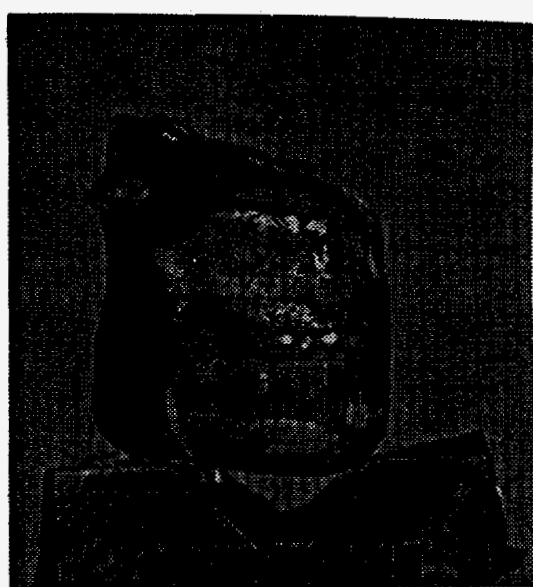

(b)

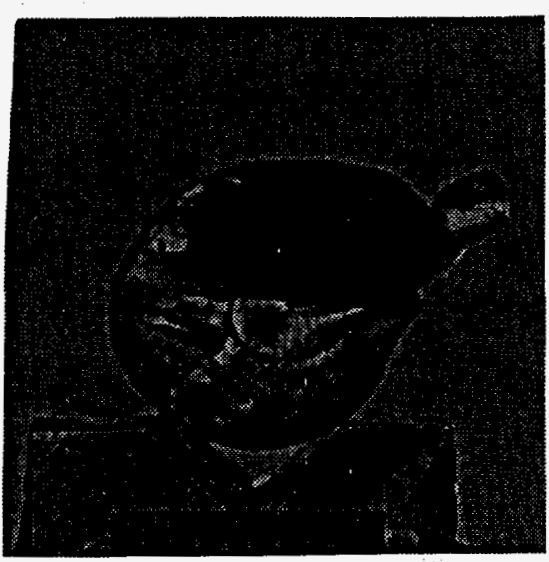

(c)

Figure 5. A large piece of the vent cup of SC0092 was sheared off during impact in Test RTG-2; (a) impact face, (b) trailing face, (c) vent end. 


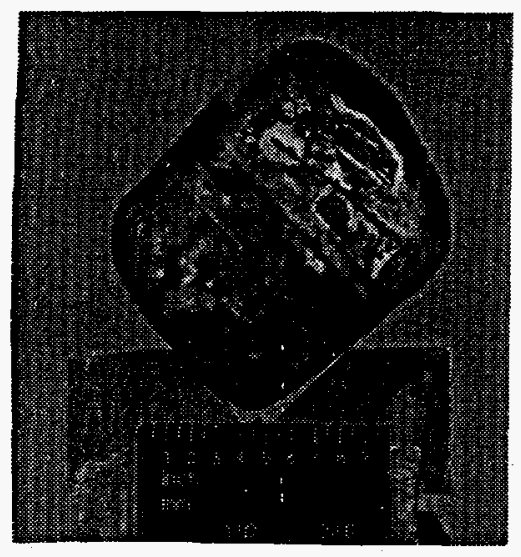

(a)

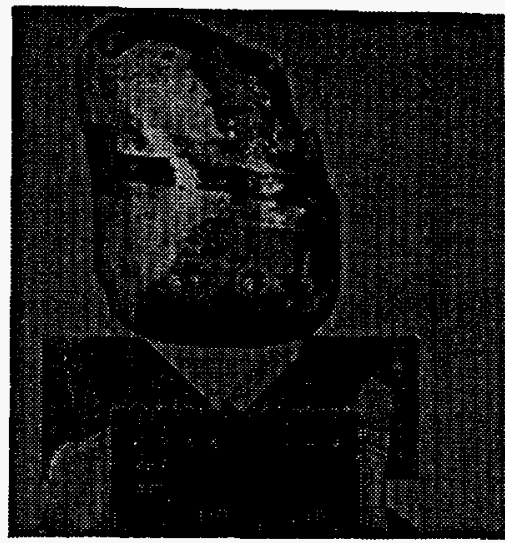

(b)

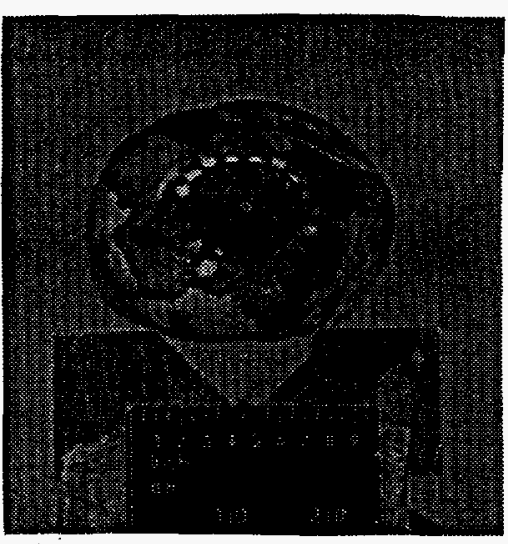

(c)

Figure 6. A transverse breaching crack was located in the vent cup on the impact face of SC0096; (a) impact face, (b) profile, (c) vent end. 